\title{
Fertility, Union Wage Setting and Social Security System
}

\author{
Leran Wang $^{1}$ \\ ${ }^{1}$ Graduate School of Economics, Keio University, Tokyo, Japan \\ Correspondence: Leran Wang, 2-15-45 Mita, Minato-ku, Tokyo, Japan. Tel: 8180-4843-0925. E-mail: \\ orakuzenn@gmail.com
}

Received: June 9, 2016

Accepted: June 24, 2016

Online Published: August 25, 2016

doi:10.5539/ijef.v8n9p1

URL: http://dx.doi.org/10.5539/ijef.v8n9p1

\begin{abstract}
This study analyzes how a social security system composed of a public pension, child allowances, and unemployment insurance affects endogenous fertility and unemployment when the wage level is endogenously set by monopolistic trade unions in an overlapping generations model. The analysis reveals, first, that increased pension tax rates lead to a higher fertility rate when wages are higher but a lower rate when wages are lower. Second, an increased child allowances tax rates lead to an increased fertility rate when wages are lower but a decreased rate when wages are higher. Therefore, both social security and wage setting should be considered in order to improve fertility and reduce unemployment.
\end{abstract}

Keywords: fertility, unemployment, trade unions, social security, overlapping generations model

\section{Introduction}

Many European countries are plagued with high unemployment during recent decades. Moreover, the aging population is also a common problem faced by many countries. Since unemployment is often viewed as a short-run problem due to business cycle, while fertility is considered as a long-run issue, they are often discussed separately (Note 1). However, the existing unemployment of Europe is attributed to equilibrium unemployment (Bean, 1994), which does not disappear in the long run (Bräuninger, 2000), this thereby brings significant research value to consider fertility and unemployment simultaneously (Note 2).

To deal with problems of falling fertility, an aging population or increasing unemployment, many policy makers and economists consider social security systems (SSS) as effective tools. However, in-depth analyses reveal many contradictions when SSS are applied: governments' attempts to apply unemployment insurance to improve the living standards of the unemployed may cause the tax burden of social security to increase the unemployment rate; pay-as-you-go (PAYG) pensions have been blamed for declining fertility rates; child allowances used to increase fertility rates can impose a tax burden that reduces capital accumulation, hindering economic growth. Therefore, can we solve the problems of fertility and unemployment by employing the SSS properly?

Previous literature have attempted to analyze effect of SSS on fertility in an imperfect labor market with unemployment, and put forward policy advices in applying SSS. Fanti and Gori (2007) showed that for any given minimum (or union's) wage value, the child subsidy reduces capital accumulation and increases unemployment, and ultimately decreases demand to bear children in a closed economy. Fanti and Gori (2012) examined the effect of child allowances on fertility in a small open economy, and find that in the context of competitive labor market, it acts as a fertility-enhancing device, while in a unionized market the child policy may be ineffective. But both of them failed to suggest how to increase fertility and decrease unemployment by using child policy. To put forward the policy suggestions, Wang (2015) discussed the effect of a SSS on fertility and unemployment by assuming a constant minimum wage, concluding that a pension alone or the combination of a pension and child allowances may positively affect fertility and reduce unemployment. However, the assumption of constant minimum wage is lack of correspondence with reality. Consequently, it motivates this study to extend Wang (2015) by incorporating some institutional features of European countries, thus assuming that wage levels are endogenously set by monopolistic trade unions (Note 3). This study finds that not only the way to employ the SSS, but also the consideration of wage setting influence the effect of pensions or child allowances on fertility and unemployment.

The model of this current work has several peculiarities. Firstly, wages are set by the monopolistic unions. Unions maximize the expected utility of the representative members. Therefore, in a closed economy, the interest 
rate which is related to wage level affects the present discounted value of pension's level. This mechanism implies that wage setting is an important factor to be considered in the effect analysis of SSS on fertility and unemployment (Note 4). Secondly, SSS are composed of pension, child allowances and unemployment insurance aiming to address problems of fertility and unemployment. Taking into account the demographic features, the social security system involves pension and child allowances: when progeny is looked upon as a consumption good, child allowances can be used to reduce the costs of childrearing (Barro \& Becker, 1988; Galor \& Weil, 1996); when child is treated as a capital good, sufficient pension benefits in old age will attenuate the function of offspring, which abates the incentive to rear children(Cigno, 1993); since the more children, the more tax payers of PAYG-basis transfer, children are often regarded as a public capital good, by which governments encourage higher fertility (Folbre, 1994; Van Groezen et al., 2003) (Note 5). Moreover, unemployment insurance is incorporated to ensure the lives of the unemployed. This study reveals that, first, increased pension levels lead to a higher fertility rate when wages are higher but a lower rate when wages are lower. Second, an increased child allowances leads to an increased fertility rate when wages are lower but a decreased rate when wages are higher.

The remainder of this paper is organized as follows. Section 2 presents the model. Section 3 discusses the equilibrium. Section 4 describes a set of comparative statics analyzing the effects of pensions and child allowances, and presents simulation. Section 5 gives a conclusion.

\section{The Model}

\subsection{Individuals}

Consider a two-period OLG model in a closed economy. Individuals gain utility from youth consumption $\left(c_{1, t}\right)$, old-age consumption $\left(c_{2, t+1}\right)$, and child rearing. The maximization problem is

$$
\max U\left(c_{1, t}, c_{2, t+1}, n_{t}\right)=\ln \left(c_{1, t}\right)+\beta \ln \left(c_{2, t+1}\right)+\gamma \ln \left(n_{t}\right)
$$

subject to

$$
\begin{gathered}
c_{1, t}+s_{t}=\omega_{t}(1-\tau-\rho-\varepsilon)\left(1-u_{t}\right)+\sigma_{t} u_{t}-\left(m-\varphi_{t}\right) n_{t} \\
c_{2, t+1}=s_{t}\left(1+r_{t+1}\right)+\theta_{t}
\end{gathered}
$$

where $n_{t}$ denotes the children's number, and $N_{t} n_{t}=N_{t+1}\left(n_{t}>0\right) ; \beta$ and $\gamma$ are the weights of $c_{2, t+1}$ and $n_{t}$. $\tau, \rho, \varepsilon$ are the tax rates for public pensions $\left(\theta_{t}\right)$, child allowances $\left(\varphi_{t}\right)$ and unemployment insurance $\left(\sigma_{t}\right) ; m$ is the average child-rearing cost (Van Groezen et al., 2003; Van Praag \& Warnaar, 1997); $s_{t}$ is savings.

Taxes on workers' income are used to finance the public pensions, child allowances and unemployment benefits. In this study, separated balanced budgets are assumed (Note 6). For the public pension, $\tau \omega_{t} n_{t-1}\left(1-u_{t}\right)=\theta_{t}$. For the child allowances, $\rho \omega_{t}\left(1-u_{t}\right)=\varphi_{t} n_{t}$. For the unemployment insurance, $\varepsilon \omega_{t}\left(1-u_{t}\right)=\sigma_{t} u_{t}$. Therefore, savings and fertility are given by:

$$
\begin{gathered}
s_{t}=\frac{\omega_{t}\left(1-u_{t}\right)}{1+\beta+\gamma}\left[\beta(1-\tau-\rho)-\frac{\tau n_{t-1}(1+\gamma)}{1+r_{t+1}}\right] \\
n_{t}=\frac{\omega_{t}\left(1-u_{t}\right)}{1+\beta+\gamma} \cdot \frac{\gamma}{m-\varphi_{t}}\left[(1-\tau-\rho)+\frac{\tau n_{t-1}}{1+r_{t+1}}\right]
\end{gathered}
$$

The capital market's clearing condition is $k_{t+1}=s_{t} / n_{t}$. Therefore,

$$
k_{t+1}=\frac{\beta\left(m-\varphi_{t}\right)}{\gamma}-\frac{\tau n_{t-1}(1+\beta+\gamma)}{(1-\tau-\rho)\left(1+r_{t+1}\right)+\tau n_{t-1}}
$$

\subsection{Firms}

The Cobb-Douglas production function is $Y_{t}=K_{t}{ }^{\delta} L_{t}{ }^{1-\delta} . K_{t}$ and $L_{t}$ denote the capital and labor input. $\delta \in(0,1)$ represents the weight of the capital input. $L_{t}=N_{t}\left(1-u_{t}\right)$, where $N_{t}$ is the population of generation $t$, and $u_{t}$ is the unemployment rate. The profit function is:

$$
\pi_{t}=Y_{t}-r_{t} K_{t}-\omega_{t} L_{t}
$$

Therefore, to maximize profits, the labor and capital demand level are:

$$
\begin{gathered}
L_{t}: \quad \omega_{t}=(1-\delta)\left(\frac{K_{t}}{L_{t}}\right) \delta=(1-\delta)\left(\frac{k_{t}}{1-u_{t}}\right) \delta \\
K_{t}: \quad r_{t}=\delta\left(\frac{K_{t}}{L_{t}}\right)^{\delta-1}-1=\delta\left(\frac{k_{t}}{1-u_{t}}\right)^{\delta-1}-1
\end{gathered}
$$


where $k_{t}=K_{t} / N_{t}$. Therefore, $1+r_{t+1}=\delta\left(\omega_{t+1} / 1-\delta\right)^{\frac{\delta-1}{\delta}}$.

\subsection{Unions}

Wages are set by monopolistic trade unions. It is assumed that the unions can either set wages or take the interest rate and fiscal policy as given. The members of the trade unions have the possibility $u_{t}$ to lose their job. The objective is to set wage levels to maximize the lifetime income of their members (Note 7):

$$
\max _{t}=N_{t}\left(1-u_{t}\right)\left\{\omega_{t}(1-\tau-\rho-\varepsilon)+\frac{\theta_{t}}{1+r_{t+1}}\right\}+N_{t} u_{t}\left\{\sigma_{t}+\frac{\theta_{t}}{1+r_{t+1}}\right\}
$$

Substitute the labor demand in Eq. (4) to the equation above, then (Note 8)

$$
\omega_{t}=\frac{1}{(1-\delta)(1-\tau-\rho-\varepsilon)} \sigma_{t}
$$

which is the wage level for the equilibrium unemployment. Thus, unions set wages based on the level of unemployment benefits and social security tax rates (Ono, 2010).

\section{Equilibrium}

From Eq. (2), (3), and (6),

$$
\begin{gathered}
\frac{\omega_{\mathrm{t}}\left(1-u_{t}\right)}{m n_{t}-\rho \omega_{\mathrm{t}}\left(1-u_{t}\right)}\left[(1-\tau-\rho)+\frac{\tau n_{t-1}}{\delta\left(\frac{\omega_{\mathrm{t}+1}}{1-\delta}\right)^{\frac{\delta-1}{\delta}}}\right]=\frac{1+\beta+\gamma}{\gamma} \\
\left(\frac{\omega_{\mathrm{t}+1}}{1-\delta}\right)^{\frac{1}{\delta}}\left(1-u_{t+1}\right)=\frac{\beta\left(m-\frac{\rho \omega_{t}\left(1-u_{t}\right)}{n_{t}}\right)}{\gamma}-\frac{\tau n_{t-1}(1+\beta+\gamma)}{(1-\tau-\rho) \delta\left(\frac{\omega_{\mathrm{t}+1}}{1-\delta}\right)^{\frac{\delta-1}{\delta}}+\tau n_{t-1}} \\
\frac{\varepsilon\left(1-u_{t}\right)}{u_{t}}=(1-\delta)(1-\tau-\rho-\varepsilon)
\end{gathered}
$$

From Eq. (6a),

$$
u_{t}=u=\frac{\varepsilon}{\varepsilon+(1-\delta)(1-\tau-\rho-\varepsilon)}
$$

Therefore, when the social security tax increases, unemployment will increase (Daveri \& Tabellini, 2000; Nickell \& Layard, 1999) (Note 9). From Eq. (6b) and (2a),

$$
\frac{m(1+\beta+\gamma)}{\gamma(1-u)} \frac{n_{t}}{\omega_{t}}-\frac{\gamma(1-\tau)+\rho(1+\beta)}{\gamma}=\frac{\tau n_{t-1}}{\delta\left(\frac{\omega_{t+1}}{1-\delta}\right)^{\frac{\delta-1}{\delta}}}
$$

Substituting (2b) into (3a) in terms of $n_{t} / \omega_{t}$,

$$
\frac{\left(\frac{\omega_{t+1}}{1-\delta}\right)^{\frac{1}{\delta}}(1-u)}{1+\beta+\gamma}=\frac{m \beta}{\gamma(1+\beta+\gamma)}-\frac{m \beta \rho \delta\left(\frac{\omega_{t+1}}{1-\delta}\right)^{\frac{\delta-1}{\delta}}}{\gamma^{2}\left\{\tau n_{t-1}+\left[1-\tau+\frac{\rho(1+\beta)}{\gamma}\right] \delta\left(\frac{\omega_{t+1}}{1-\delta}\right)^{\frac{\delta-1}{\delta}}\right\}}-\frac{\tau n_{t-1}}{\tau n_{t-1}+(1-\tau-\rho) \delta\left(\frac{\omega_{t+1}}{1-\delta}\right)^{\frac{\delta-1}{\delta}}}
$$

Lemma. From the implicit function theorem, the relationship between fertility and wage levels can be written as the function $f: n_{t-1}=f\left(\omega_{t+1}\right)$.

Proof. See Appendix 2.

From Eq. (2b) and Lemma, the dynamics of wage equilibrium is

$$
\frac{m(1+\beta+\gamma)}{\gamma(1-u)} \frac{f\left(\omega_{t+2}\right)}{\omega_{t}}-\frac{\gamma(1-\tau)+\rho(1+\beta)}{\gamma}=\frac{\tau f\left(\omega_{t+1}\right)}{\delta\left(\frac{\omega_{t+1}}{1-\delta}\right)^{\frac{\delta-1}{\delta}}}
$$

This paper's analysis focuses on the steady state. In steady state,

$$
f(\omega)\left[\frac{m(1+\beta+\gamma)}{\gamma(1-u)} \frac{1}{\omega}-\frac{\tau}{\delta\left(\frac{\omega}{1-\delta}\right)^{\frac{\delta-1}{\delta}}}\right]=\frac{\gamma(1-\tau)+\rho(1+\beta)}{\gamma}
$$


$f(\omega)>0$, therefore $\frac{m(1+\beta+\gamma)}{\gamma(1-u)} \frac{1}{\omega}-\frac{\tau}{\delta\left(\frac{\omega}{1-\delta}\right)^{\delta-1}}>0, \omega<\left[\frac{m \delta(1+\beta+\gamma)}{\gamma \tau(1-u)}\right]^{\delta}(1-\delta)^{1-\delta}$, which ensures that interest rates not to fall too low, and capital accumulation is nonnegative.

\section{Effects of Social Security on Fertility}

\subsection{Public Pension's Effect on Fertility}

Differentiating Equation (8) with the public pension tax rate produces

$$
\frac{\partial f(\omega)}{\partial \tau}\left[\frac{m(1+\beta+\gamma)}{\gamma(1-u)} \frac{1}{\omega}-\frac{\tau}{\delta\left(\frac{\omega}{1-\delta}\right)^{\frac{\delta-1}{\delta}}}\right]=-\frac{M}{\left[m(1+\beta+\gamma) \delta\left(\frac{\omega}{1-\delta}\right)^{\frac{\delta-1}{\delta}}-\tau \omega \gamma(1-u)\right] \gamma(1-u)[\varepsilon+(1-\delta)(1-\tau-\rho-\varepsilon)]^{2}}
$$

where $\quad M=m(1+\beta+\gamma) \delta\left(\frac{\omega}{1-\delta}\right)^{\frac{\delta-1}{\delta}}\left\{\gamma(1-u)[\varepsilon+(1-\delta)(1-\tau-\rho-\varepsilon)]^{2}+\varepsilon(1-\delta)[\gamma(1-\tau)+\rho(1+\beta)]\right\}-\left\{\omega(1-u)^{2}[\varepsilon+\right.$ $\left.(1-\delta)(1-\tau-\rho-\varepsilon)]^{2}\left[\gamma^{2}+\rho(1+\beta) \gamma\right]\right\}$.

\section{Proposition 1.}

For wages endogenously set by trade unions, when the public pension tax rate increases, the fertility rate is affected as follows:

(i) If $\tau \varepsilon>(1-\tau-\rho-\varepsilon)[\varepsilon+(1-\delta)(1-\tau-\rho-\varepsilon)]$, (i.e., $\left.A>B_{\tau}\right)$, fertility will decrease when the wage level is below $B_{\tau}$;

(ii) If $\tau \varepsilon<(1-\tau-\rho-\varepsilon)[\varepsilon+(1-\delta)(1-\tau-\rho-\varepsilon)]$, (i.e., $\left.A<B_{\tau}\right)$, fertility will increase when the wage level is between $A$ and $B_{\tau}$, and decrease when the wage level is below $A$ (Note 10).

Here, $A=\left(\frac{m(1+\beta+\gamma) \delta\left\{\gamma(1-u)[\varepsilon+(1-\delta)(1-\tau-\rho-\varepsilon)]^{2}+\varepsilon(1-\delta)[\gamma(1-\tau)+\rho(1+\beta)]\right\}}{\gamma[\gamma+\rho(1+\beta)](1-u)^{2}[\varepsilon+(1-\delta)(1-\tau-\rho-\varepsilon)]^{2}}\right)^{\delta}(1-\delta)^{1-\delta}, B_{\tau}=\left[\frac{m \delta(1+\beta+\gamma)}{\gamma \tau(1-u)}\right]^{\delta}(1-$ $\delta)^{1-\delta}$.

Proof. See Appendix 3.

Equation (2) is rewritten as

$$
n_{t}=\frac{\omega_{t} \frac{(3)}{\left.1+\beta+u_{t}\right)}}{1+\beta+\gamma} \cdot \frac{\gamma}{m-\varphi_{t}}\left[(1 \stackrel{(1)}{\stackrel{(-\tau}{\tau}}-\rho)+\stackrel{\stackrel{2}{\tau_{t-1}}}{1+r_{t+1}}\right]
$$

A pension can be seen as a social security tax (part (1)) and future income (part (2)). The former part reduces society's average income level and thus negatively affects fertility (the "tax effect;" part (1)); the latter part increases income, and, when wages are set at a higher level $\left(\leq B_{\tau}\right)$, the interest rate becomes lower and the present discounted value of the pension becomes higher, which positively affects fertility: the higher the wage, the greater the positive effect (the "income effect;" part (2)). Moreover, when the public pension tax rate increases, the unemployment rate will also increase (Eq. [6b]), reducing fertility (the "unemployment effect;" part (3)).

Therefore, when the wage level is set higher, the income effect is larger, the synthesized effect of parts (1) and (2) is positive and large enough, the negative part (3) effect is covered, and the final effect is positive. When the wage level is set lower, the positive synthesized effect is smaller than that of part (3) or the synthesized effect is negative, the final effect is negative. Consequently, when individuals are guaranteed high old-age benefits with higher wages, they have a stronger desire to raise more children, improving fertility rates; otherwise, the desire for children is suppressed, and people save money for themselves instead, reducing fertility. Therefore, governments seeking to decrease unemployment and increase fertility rates should reduce pension tax rates and set wages lower.

\subsection{Child Allowances' Effect on Fertility}

Differentiating Equation (8) with the child allowances tax rate produces

$$
\frac{\partial f(\omega)}{\partial \rho}\left[\frac{m(1+\beta+\gamma)}{\gamma(1-u)} \frac{1}{\omega}-\frac{\tau}{\delta\left(\frac{\omega}{1-\delta}\right) \frac{\delta-1}{\delta}}\right]=\frac{N}{\left[m(1+\beta+\gamma) \delta\left(\frac{\omega}{1-\delta}\right)^{\frac{\delta-1}{\delta}}-\omega(1-u) \gamma \tau\right] \gamma(1-u)[\varepsilon+(1-\delta)(1-\tau-\rho-\varepsilon)]^{2}}
$$


where $\quad N=m(1+\beta+\gamma) \delta\left(\frac{\omega}{1-\delta}\right) \frac{\delta-1}{\delta} X-\omega \gamma \tau(1+\beta)(1-u)^{2}[\varepsilon+(1-\delta)(1-\tau-\rho-\varepsilon)]^{2}, \quad X=(1+$ $\beta)(1-u)[\varepsilon+(1-\delta)(1-\tau-\rho-\varepsilon)]^{2}-\varepsilon(1-\delta)[\gamma(1-\tau)+\rho(1+\beta)]$.

\section{Proposition 2.}

For wages endogenously set by trade unions, when the child allowances tax rate increases, the fertility rate is affected as follows:

(i) If $(1+\beta)(1-\tau-\rho-\varepsilon)[\varepsilon+(1-\delta)(1-\tau-\rho-\varepsilon)]<\varepsilon[\gamma(1-\tau)+\rho(1+\beta)]$, fertility will decrease when wages are set below $B_{\rho}$;

(ii) If $(1+\beta)(1-\tau-\rho-\varepsilon)[\varepsilon+(1-\delta)(1-\tau-\rho-\varepsilon)]>\varepsilon[\gamma(1-\tau)+\rho(1+\beta)]$, fertility will increase when wages are set below $C$, and decrease when wages are set between $C$ and $B_{\rho}$ (Note 11).

Here, $C=\left(\frac{m(1+\beta+\gamma) \delta}{\tau \gamma(1-u)}-\frac{m(1+\beta+\gamma) \delta \varepsilon(1-\delta)[\gamma(1-\tau)+\rho(1+\beta)]}{\gamma \tau(1-u)^{2}(1+\beta)[\varepsilon+(1-\delta)(1-\tau-\rho-\varepsilon)]^{2}}\right)^{\delta}(1-\delta)^{1-\delta}, B_{\rho}=\left[\frac{m(1+\beta+\gamma) \delta}{\tau \gamma(1-u)}\right]^{\delta}(1-\delta)^{1-\delta}$.

Proof. See Appendix 4.

Equation (2) is rewritten as

$$
n_{t}=\frac{\overbrace{-\rho \omega_{t}\left(1-u_{t}\right) \gamma n_{t}}^{1}+n_{t} \gamma \omega_{t} \overbrace{\left(1-u_{t}\right)\left[(1-\tau)+\frac{\tau n_{t-1}}{1+r_{t+1}}\right]}^{\text {(3) }}}{\underbrace{-\rho \omega_{t}\left(1-u_{t}\right)(1+\beta+\gamma)}_{(2)}+m n_{t}(1+\beta+\gamma)}
$$

As in pension analysis, the child allowances are a social security tax and also a benefit. Thus, the part (1) means "tax effect," and part (2) means "income effect." The latter is stronger than the former (Note 12). For part (3), the arguments in the first parenthese means "unemployment effect", and the ones in brackets "dependent effect," because it depends on the discounted value of the pension. If wages are set higher, the present discounted value of the pension increases, and the negative part (3) effect is increased, causing the overall effect on fertility to be negative when the negative effect is bigger than the synthesized effect of part (1) and part (2); if wages are set lower, the negative part (3) effect decreases, and the final effect on fertility could be positive.

The analysis of Proposition 2 shows that the effect of child allowances on fertility correlates with the wage level. Increases in child allowance tax rate will deteriorate the unemployment state: higher wages induce higher future old-age pension income, increasing the negative effect of unemployment on fertility, thus suppressing the desire to have more children; lower wages reduce the old-age pension income, decreasing the negative effect of unemployment on fertility, thus encouraging the desire to have more children. Therefore, governments seeking to reduce unemployment and improve fertility could reduce the child allowance tax rate when wages are set higher.

This conclusion differs from that of Wang (2015) because of the different assumptions. Wang (2015) assumed that the minimum wage is constant, the interest rate is also constant, the present discounted value is therefore affected by the pension's level. In this study, however, not only pension level but also the wage level affects the value; hence, the wage setting affects how the social security system influence fertility and unemployment.

\subsection{Simulation}

To illustrate the two propositions, simulation parameters are set as shown in Table 1. Proposition 1 (i) and (ii) are shown in Figures 1 and 2, and Proposition 2 (i) and (ii) are shown in Figures 3 and 4.

Table 1. Parameters set in simulations

\begin{tabular}{|c|c|c|c|c|c|c|c|}
\hline & $\tau$ & $\rho$ & $\varepsilon$ & $A$ & $B$ & $C$ & $\omega_{t}$ \\
\hline Figure 1 & $0.35 \sim 0.49$ & 0.2 & 0.25 & & $1.18 \sim 2.42$ & & $0.8,1,1.1$ \\
\hline Figure 2 & $0.2 \sim 0.34$ & 0.15 & 0.05 & $0.55 \sim 0.57$ & $1.01 \sim 0.86$ & & $0.7,0.6,0.5,0.4$ \\
\hline Figure 3 & 0.35 & $0.1 \sim 0.24$ & 0.40 & & $1.37 \sim 3.13$ & & $0.8,1,1.1$ \\
\hline Figure 4 & 0.2 & $0.1 \sim 0.24$ & 0.1 & & $1.04 \sim 1.07$ & $1.01 \sim 0.98$ & $1.03,1.02,0.97,0.8$ \\
\hline
\end{tabular}




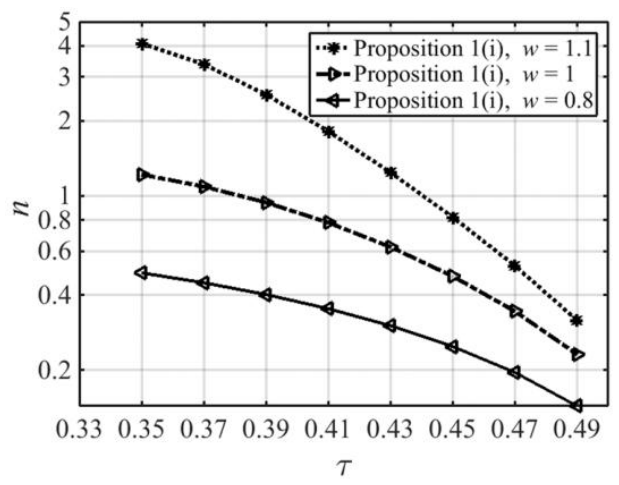

Figure 1. Public pension's effect on fertility (1)

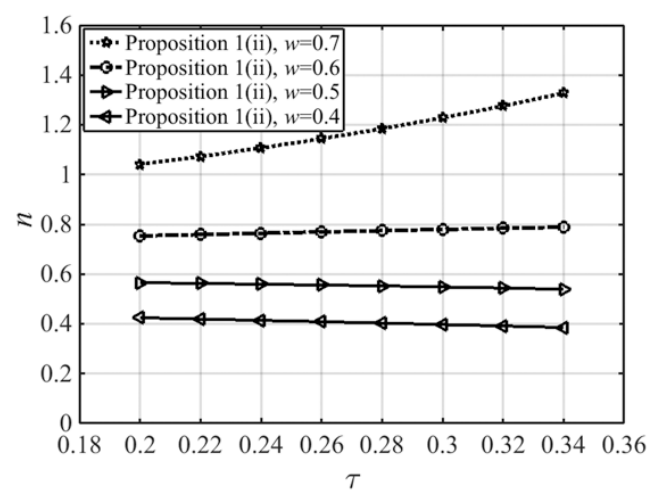

Figure 2. Public pension's effect on fertility (2)

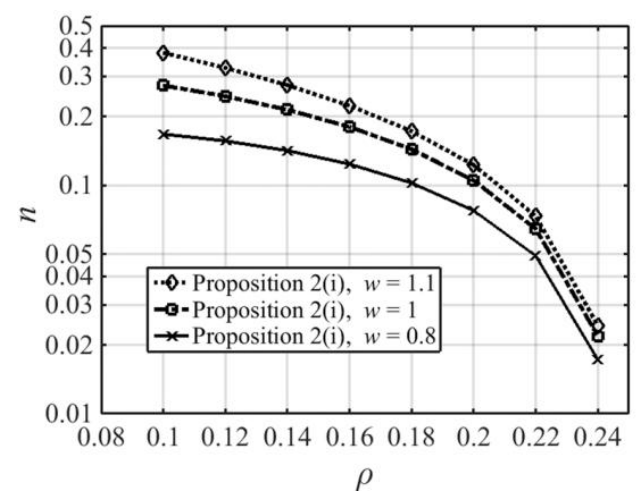

Figure 3. Child allowances' effect on fertility (1)

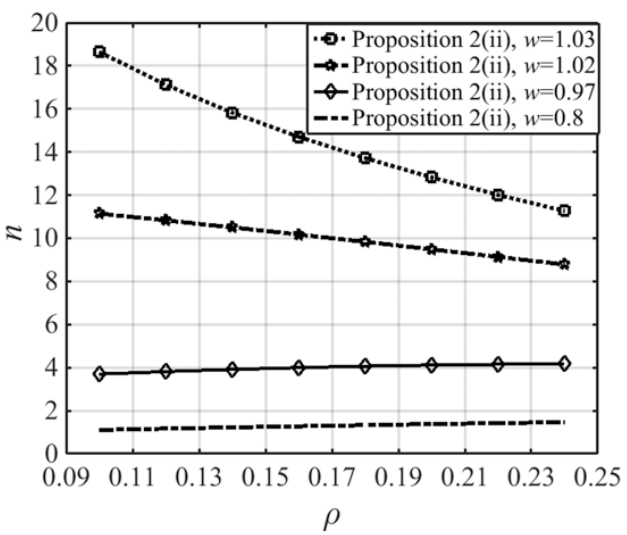

Figure 4. Child allowances' effect on fertility (2) 
The four figures above show that the simulation results accord with the two propositions. Propositions 1 (ii) and 2 (ii) are realistically plausible.

\section{Conclusion}

Governments seeking to reduce unemployment rate and improve fertility rate should lower the tax rates of the social security system to improve employment, and use pension and unemployment insurance together to improve fertility when wages are set lower or use child allowances and unemployment insurance together to improve fertility when wages are set higher.

\section{Acknowledgements}

The author is grateful to Professor Yasuo Maeda, Professor Keiichiro Kobayashi and Professor Hikaru Ogawa for their generous guidance and suggestions and appretiates the support from the Keio University Doctorate Student Grant-in-Aid Program and Chinese Scholarship Council to this study.

\section{References}

Adsera, A. (2004). Changing fertility rates in developed countries. The impact of labor market institutions. Journal of Population Economics, 17(1), 17-43. http://dx.doi.org/10.1007/s00148-003-0166-x

Adsera, A. (2011). Where are the babies? Labor market conditions and fertility in Europe. European Journal of Population/Revue européenne de Démographie, 27(1), 1-32. http://dx.doi.org/10.1007/s10680-010-9222-x

Ahn, N., \& Mira, P. (2001). Job bust, baby bust?: Evidence from Spain. Journal of Population Economics, 14(3), 505-521. http://dx.doi.org/10.1007/s001480100093

Barro, R., \& Becker, G. (1988). A Reformulation of the Economic Theory of Fertility. Quarterly Journal of Economics. http://dx.doi.org/10.2307/1882640

Bean, C. R. (1994). European unemployment: A survey. Journal of Economic Literature, 573-619.

Bräuninger, M. (2000). Wage bargaining, unemployment, and growth. Journal of Institutional and Theoretical Economics (JITE)/Zeitschrift für Die Gesamte Staatswissenschaft, 646-660.

Bräuninger, M. (2005). Social security, unemployment, and growth. International Tax and Public Finance, 12(4), 423-434. http://dx.doi.org/10.1007/s10797-005-1823-7

Cigno, A. (1993). Intergenerational transfers without altruism: Family, market and state. European Journal of Political Economy, 9(4), 505-518. http://dx.doi.org/10.1016/0176-2680(93)90036-T

Corneo, G., \& Marquardt, M. (2000). Public pensions, unemployment insurance, and growth. Journal of Public Economics, 75(2), 293-311. http://dx.doi.org/10.1016/S0047-2727(99)00058-4

Daveri, F., \& Tabellini, G. (2000). Unemployment, growth and taxation in industrial countries. Economic Policy, 15(30), 47-104. http://dx.doi.org/10.1111/1468-0327.00057

Fanti, L., \& Gori, L. (2007). Income taxation, child-rearing policies, fertility and unemployment. Economics Bulletin, 10(18), 1-10.

Fanti, L., \& Gori, L. (2012). A note on child policy and fertility in an overlapping generations small open economy: When the labour market institutions matter. International Journal of Population Research. http://dx.doi.org/10.1155/2012/875310

Fenge, R., \& Meier, V. (2005). Pensions and fertility incentives. Canadian Journal of Economics/Revue Canadienne D'économique, 38(1), 28-48. http://dx.doi.org/ 10.1111/j.0008-4085.2005.00267.x

Fenge, R., \& Meier, V. (2009). Are family allowances and fertility-related pensions perfect substitutes? International Tax and Public Finance, 16(2), 137-163. http://dx.doi.org/ 10.1007/s10797-007-9060-x

Folbre, N. (1994). Children as public goods. The American Economic Review, 86-90. http://dx.doi.org/10.1111/papa.12019

Galor, O., \& Weil, D. (1996). The Gender gap, Fertility and Economic Growth. The American Economic Review, 86(3), 374-387.

Nickell, S., \& Layard, R. (1999). Labor market institutions and economic performance. Handbook of Labor Economics, 3, 3029-3084. http://dx.doi.org/10.1016/S1573-4463(99)30037-7

Ono, T. (2007). Unemployment dynamics in an OLG economy with public pensions. Economic Theory, 33(3), 549-577. http://dx.doi.org/10.1007/s00199-006-0150-2 
Ono, T. (2010). Growth and unemployment in an OLG economy with public pensions. Journal of Population Economics, 23(2), 737-767. http://dx.doi.org/10.1007/s00148-008-0225-4

Oswald, A. J. (1982). The microeconomic theory of the trade union. The Economic Journal, 576-595. http://dx.doi.org/10.1007/978-94-011-2378-5_1

Van Groezen, B., \& Meijdam, L. (2008). Growing old and staying young: Population policy in an ageing closed economy. Journal of Population Economics, 21(3), 573-588. http://dx.doi.org/ 10.1007/s00148-006-0067-x

Van Groezen, B., Leers, T., \& Meijdam, L. (2003). Social security and endogenous fertility: Pensions and child allowances as Siamese twins. Journal of Public Economics, 87(2), 233-251. http://dx.doi.org/10.1016/S0047-2727(01)00134-7

Van Praag, B. M., \& Warnaar, M. F. (1997). The cost of children and the use of demographic variables in consumer demand. Handbook of Population and Family Economics, 1, 241-273. http://dx.doi.org/10.1016/S1574-003X(97)80023-2

Wang, L. (2015). Fertility and unemployment in a social security system. Economics Letters. http://dx.doi.org/10.1016/j.econlet.2015.05.014

Žamac, J. (2007). Pension design when fertility fluctuates: The role of education and capital mobility. Journal of Public Economics, 91(3), 619-639. http://dx.doi.org/10.1016/j.jpubeco.2006.09.013

\section{Notes}

Note 1. See Corneo and Marquardt (2000), Bräuninger (2005), Ono (2007) and Ono (2010) for unemployment and SSS; see Van Groezen, Leers, and Meijdam (2003) for fertility and SSS.

Note 2. See Adsera (2004); Ahn and Mira (2001); Daveri and Tabellini (2000); Adsera (2011).

Note 3. Ono (2007) gives a deep and complete analysis on 'employment effects of public pensions via capital accumulation and union wage setting' and concludes that a higher contribution rate results in a lower unemployment rate. As his work assumes exogenous fertility, it also motivates this study to dwell on the situation when fertility is endogenous.

Note 4. Wang (2015) analyzed the effect of pension and child allowances in the context of constant minimum wage, which makes the future pension level only hinging on pension level. In this paper, the wage setting process gives a sophisticated analysis incorporating wage variation.

Note 5. Van Groezen et al. (2003) argued that PAYG pension and child allowances should be enforced together to realize a Pareto-improvement intergenerational redistribution.

Note 6. See Fenge and Meier (2005, 2009); Van Groezen et al. (2003); Van Groezen and Meijdam (2008); Žamac (2007).

Note 7. See Oswald (1982); Daveri and Tabellini (2000); Daveri and Tabellini (2000); Ono (2010).

Note 8. See Appendix 1.

Note 9. $\frac{\partial u}{\partial \varepsilon}=\frac{(1-\delta)(1-\tau-\rho)}{[\varepsilon+(1-\delta)(1-\tau-\rho-\varepsilon)]^{2}}>0, \frac{\partial u}{\partial \tau}=\frac{\varepsilon(1-\delta)}{[\varepsilon+(1-\delta)(1-\tau-\rho-\varepsilon)]^{2}}>0, \frac{\partial u}{\partial \rho}=\frac{\varepsilon(1-\delta)}{[\varepsilon+(1-\delta)(1-\tau-\rho-\varepsilon)]^{2}}>0$.

Note 10. In Proposition 1, the second situation (ii) is more plausible, which will be showed in simulation part.

Note 11. In Proposition 2, the second situation (ii) is more plausible, which will be showed in simulation part.

Note 12. $|(2)|-|1| \mid=\rho \omega_{t}\left(1-u_{t}\right)\left[1+\beta+\gamma-\gamma n_{t}\right]>0$.

\section{Appendix}

\section{Appendix 1}

$$
V_{t}=L_{t}\left\{\omega_{t}(1-\tau-\rho-\varepsilon)+\frac{\theta_{t}}{1+r_{t+1}}\right\}+\left(N_{t}-L_{t}\right)\left\{\sigma_{t}+\frac{\theta_{t}}{1+r_{t+1}}\right\}
$$

From equation (1), the labor demand can be derived as: 


$$
L_{t}=K_{t}\left(\frac{1-\delta}{\omega_{t}}\right)^{\frac{1}{\delta}}
$$

Substituting the equation above into the objective equation of the trade union produces.

$$
\begin{aligned}
& V_{t}=K_{t}\left(\frac{1-\delta}{\omega_{t}}\right)^{\frac{1}{\delta}}\left\{\omega_{t}(1-\tau-\rho-\varepsilon)+\frac{\theta_{t}}{1+r_{t+1}}\right\}+\left(N_{t}-K_{t}\left(\frac{1-\delta}{\omega_{t}}\right)^{\frac{1}{\delta}}\right)\left\{\sigma_{t}+\frac{\theta_{t}}{1+r_{t+1}}\right\} \\
& \frac{\partial V_{t}}{\partial \omega_{t}}=K_{t}(1-\delta)^{\frac{1}{\delta}}\left(-\frac{1}{\delta}\right) \omega_{t}^{-\frac{1}{\delta}-1}\left[\omega_{t}(1-\tau-\rho-\varepsilon)+\frac{\theta_{t}}{1+r_{t+1}}\right]+K_{t}(1-\delta)^{\frac{1}{\delta}} \omega_{t}^{-\frac{1}{\delta}}(1-\tau-\rho-\varepsilon) \\
& +\left(-K_{t}\right)(1-\delta)^{\frac{1}{\delta}}\left(-\frac{1}{\delta}\right) \omega_{t}^{-\frac{1}{\delta}-1}\left[\sigma_{t}+\frac{\theta_{t}}{1+r_{t+1}}\right] \\
& =K_{t}(1-\delta)^{\frac{1}{\delta}}\left(1-\frac{1}{\delta}\right) \omega_{t}^{-\frac{1}{\delta}}(1-\tau-\rho-\varepsilon)+K_{t}(1-\delta)^{\frac{1}{\delta}} \frac{1}{\delta} \omega_{t}^{-\frac{1}{\delta}-1}\left(\sigma_{t}+\frac{\theta_{t}}{1+r_{t+1}}-\frac{\theta_{t}}{1+r_{t+1}}\right)
\end{aligned}
$$

To maximize the lifetime income of their members,

$$
\frac{\partial V_{t}}{\partial \omega_{t}}=0
$$

Therefore,

$$
\omega_{t}=\frac{1}{(1-\delta)(1-\tau-\rho-\varepsilon)} \sigma_{t}
$$

\section{Appendix 2}

Rewrite Equation (7) as:

$$
\begin{aligned}
& F\left(\omega_{t+1}, n_{t-1} ; \beta, \gamma, \delta, u, \tau\right)=0
\end{aligned}
$$

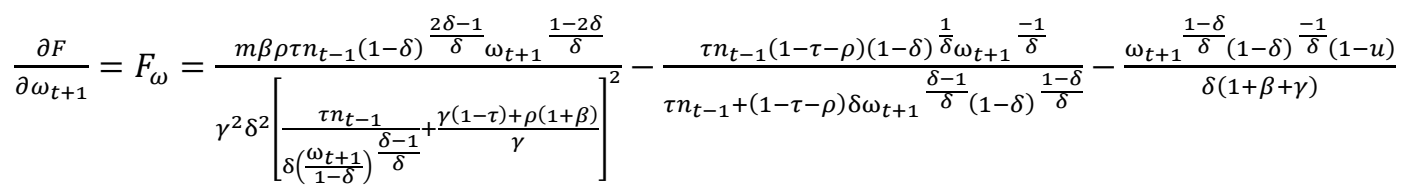

$$
\begin{aligned}
& \frac{\partial F}{\partial n_{t-1}}=F_{n}=\tau \delta\left(\frac{\omega_{t+1}}{1-\delta}\right)^{\frac{\delta-1}{\delta}} \frac{m \beta \rho\left[\tau n_{t-1}+(1-\tau-\rho) \delta\left(\frac{\omega_{t+1}}{1-\delta}\right)^{\frac{\delta-1}{\delta}}\right]^{2}-(1-\tau-\rho) \gamma^{2}\left\{\tau n_{t-1}+\left[(1-\tau)+\frac{\rho(1+\beta)}{\gamma}\right] \delta\left(\frac{\omega_{t+1}}{1-\delta}\right)^{\frac{\delta-1}{\delta}}\right\}^{2}}{\gamma^{2}\left[\tau n_{t-1}+(1-\tau-\rho) \delta\left(\frac{\omega_{t+1}}{1-\delta}\right)^{\frac{\delta-1}{\delta}}\right]^{2}\left\{\tau n_{t-1}+\left[(1-\tau)+\frac{\rho(1+\beta)}{\gamma}\right] \delta\left(\frac{\omega_{t+1}}{1-\delta}\right)^{\frac{\delta-1}{\delta}}\right\}^{2}}
\end{aligned}
$$

From Equations (A5.1) and (A5.2), we can say that Equation (13) is continuously differentiable.

As $m \beta \rho>(1-\tau-\rho) \gamma^{2}, \tau n_{t-1}+(1-\tau-\rho) \delta\left(\frac{\omega_{t+1}}{1-\delta}\right)^{\frac{\delta-1}{\delta}}<\tau n_{t-1}+\left[(1-\tau)+\frac{\rho(1+\beta)}{\gamma}\right] \delta\left(\frac{\omega_{t+1}}{1-\delta}\right)^{\frac{\delta-1}{\delta}}$, when $m \beta \rho\left[\tau n_{t-1}+(1-\tau-\rho) \delta\left(\frac{\omega_{t+1}}{1-\delta}\right)^{\frac{\delta-1}{\delta}}\right]^{2} \neq(1-\tau-\rho) \gamma^{2}\left\{\tau n_{t-1}+\left[(1-\tau)+\frac{\rho(1+\beta)}{\gamma}\right] \delta\left(\frac{\omega_{t+1}}{1-\delta}\right)^{\frac{\delta-1}{\delta}}\right\}^{2}, \quad$ which guarantees $F_{n} \neq 0$, we will derive the implicit function as

$$
n_{t-1}=f\left(\omega_{t+1}\right)
$$

\section{Appendix 3}

1. When $M>0$, then the wage level has to satisfy

$$
\omega<A \text {, }
$$

where $A=\left(\frac{m(1+\beta+\gamma) \delta\left\{\gamma(1-u)[\varepsilon+(1-\delta)(1-\tau-\rho-\varepsilon)]^{2}+\varepsilon(1-\delta)[\gamma(1-\tau)+\rho(1+\beta)]\right\}}{\gamma[\gamma+\rho(1+\beta)](1-u)^{2}[\varepsilon+(1-\delta)(1-\tau-\rho-\varepsilon)]^{2}}\right)^{\delta}(1-\delta)^{1-\delta}$. Therefore, if $\omega<A$, 
$\frac{\partial f(\omega)}{\partial \tau}<0$; if $\omega>A, \frac{\partial f(\omega)}{\partial \tau}>0$.

2. From Equation (8),

$$
\omega<B_{\tau}
$$

where $B_{\tau}=\left[\frac{m(1+\beta+\gamma) \delta}{\tau \gamma(1-u)}\right]^{\delta}(1-\delta)^{1-\delta}$;

3. When

$$
\frac{A}{B_{\tau}}=\frac{\tau \gamma(1-u)[\varepsilon+(1-\delta)(1-\tau-\rho-\varepsilon)]^{2}+\tau \varepsilon(1-\delta)[\gamma(1-\tau)+\rho(1+\beta)]}{(1-u)[\gamma+\rho(1+\beta)][\varepsilon+(1-\delta)(1-\tau-\rho-\varepsilon)]^{2}}>1
$$

ie. $\tau \varepsilon(1-\delta)>(1-u)[\varepsilon+(1-\delta)(1-\tau-\rho-\varepsilon)]^{2}$.

\section{Appendix 4}

1. If $X<0$, ie. $(1+\beta)(1-\tau-\rho-\varepsilon)[\varepsilon+(1-\delta)(1-\tau-\rho-\varepsilon)]<\varepsilon[\gamma(1-\tau)+\rho(1+\beta)]$, then

$$
\frac{\partial f(\omega)}{\partial \rho}\left[\frac{m(1+\beta+\gamma)}{\gamma(1-u)} \frac{1}{\omega}-\frac{\tau}{\delta\left(\frac{\omega}{1-\delta}\right)^{\frac{\delta-1}{\delta}}}\right]<0
$$

Thus, when $\omega<B_{\rho}, \frac{\partial f(\omega)}{\partial \rho}<0$;

2. If $X>0$,

(1) If let $N>0$, then the wage set by the unions should satisfy

$$
\omega<C
$$

where $C=\left(\frac{m(1+\beta+\gamma) \delta}{\tau \gamma(1-u)}-\frac{m(1+\beta+\gamma) \delta \varepsilon(1-\delta)[\gamma(1-\tau)+\rho(1+\beta)]}{\gamma \tau(1+\beta)(1-u)^{2}[\varepsilon+(1-\delta)(1-\tau-\rho-\varepsilon)]^{2}}\right)^{\delta}(1-\delta)^{1-\delta}$;

From Equation (8),

$$
\omega<B_{\rho}
$$

where $B_{\rho}=\left(\frac{m(1+\beta+\gamma) \delta}{\tau \gamma(1-u)}\right)^{\delta}(1-\delta)^{1-\delta}$;

And

$$
C<B_{\rho}
$$

Therefore, when $\omega<\mathrm{C}, \frac{\partial f(\omega)}{\partial \rho}>0$.

(2) If let $N<0$, then the wage level should satisfy

$$
\omega>C
$$

From Equation (8),

$$
\omega<B_{\rho}
$$

Therefore, when $\mathrm{C}<\omega<\mathrm{B}_{\rho}, \frac{\partial \mathrm{f}(\omega)}{\partial \rho}<0$.

\section{Copyrights}

Copyright for this article is retained by the author(s), with first publication rights granted to the journal.

This is an open-access article distributed under the terms and conditions of the Creative Commons Attribution license (http://creativecommons.org/licenses/by/4.0/). 